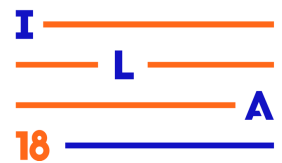

\title{
GAMIFICAÇÃO COMO INSTRUMENTO DE INTERAÇÃO PARA A EDUCAÇÃO
}

\section{GAMIFICATION AS AN INSTRUMENT OF INTERACTION FOR EDUCATION}

\author{
César Augusto Domingos Filho ${ }^{1}$, Bach. \\ Marcelo Egídio Brasileiro Do Vale ${ }^{2}$, Bach. \\ Tiago Barros Pontes e Silva ${ }^{3}$, D.Sc. \\ Francisco George de Sousa Lopes ${ }^{4}$, M.Sc.
}

(1) Universidade de Brasília (UnB)

e-mail: cesinhaobdc@gmail.com

(2) Universidade de Brasília (UnB)

e-mail: marcelo.brasileiro@me.com

(3) Universidade de Brasília (UnB)

e-mail: tiagobarros@unb.br

(4) Universidade de Brasília (UnB)

e-mail: fgeorge28@gmail.com

gamificação, design de interação, design centrado no usuário

Este trabalho descreve a solução projetada para aprimorar a interação entre alunos e professor no processo de aprendizagem de física na modalidade de Ensino de Jovens e Adultos, utilizando elementos de jogos no contexto de sala de aula.

gamification, interaction design, user-centered design

This work describes the solution designed to improve the interaction between students and teacher in the process of learning physics in the modality of Teaching Youth and Adults, using elements of games in the classroom context.

\section{Introdução}

Em um mundo pós-revolução digital pode-se constatar o impacto da velocidade da informação de diversas maneiras. Um olhar despercebido sobre tais fatos pode criar a impressão de que a sociedade chegou no auge de seu desenvolvimento para a educação, desenvolvendo estratégias como crowdlearning, aprendizado baseado em jogos e ensino a distância. Entretanto, ao analisar o ensino tradicional, o Brasil possui uma taxa de reprovação de $12 \%$ para o ensino médio (INEP, 2016), o que corresponde a mais de 906 mil jovens e adolescentes.

Pode-se constatar, a partir dessa perspectiva, que a revolução digital conferiu avanços pouco significativos para o ensino médio tradicional, uma vez que em 1997 a taxa de reprovação era de 11,4\%. $\mathrm{O}$ modelo cartesiano de ensino nas escolas tradicionais tem se tornado pouco engajador para as novas gerações, acostumadas com a velocidade da informação do mundo contemporâneo. Como um movimento a favor do ensino, novas soluções têm se mostrado necessárias para promover diversão e facilidade de entendimento para as novas gerações, aliando a curva de aprendizado à de aquisição de conhecimento dos estudantes, da mesma maneira como ocorre em jogos.

Enxergando o problema como oportunidade, novas estratégias vêm surgindo para mitigar os dados negativos. Dentre as mais inovadoras está a gamificação, que é a utilização de elementos de jogos dentro de contextos não-lúdicos para atingir um objetivo específico.

Neste sentido, o trabalho apresentado consiste no desafio de projetar uma nova experiência para as aulas de física de $2^{\circ}$ ano do ensino médio dentro do 
contexto de Ensino de Jovens e Adultos (EJA). Além de um processo centrado nos alunos, o projeto visa integração de elementos oriundos da revolução digital à sala de aula e aumento de engajamento.

O projeto foi desenvolvido nas salas de aula do Centro de Ensino 6 (CED 6) da Ceilândia, periferia de Brasília, Distrito Federal. A realização do projeto se deu nas quatro turmas de $2^{\circ}$ ano do ensino médio, totalizando cerca de 60 alunos com faixa etária variando entre 18 e 60 anos. Isso cria um desafio na medida em que a solução precisa abranger um espectro variado de idades e experiências.

Para começar a solucioná-lo, definiu-se os seguintes objetivos específicos:

- Identificar os principais problemas dentro do processo didático para os alunos de EJA do CED 6.

- Projetar uma solução gamificada que unifique os conteúdos didáticos com elementos de jogos para criar um formato mais atrativo para o ensino de física.

- Realizar uma avaliação inicial qualitativa e exploratória acerca da implementação da proposta.

O presente relato se concentra em descrever as reflexões oriundas da aplicação de um pensamento de design às estratégias de aprendizagem do conteúdo de física para o $2^{\circ}$ ano da EJA. Portanto, as investigações mais detalhadas acerca da avaliação do seu impacto no contexto escolar são realizadas por uma outra pesquisa, a qual o presente estudo é filiado.

\subsection{Educação e aprendizagem}

São frequentes as discussões a respeito de uma crise existente na educação atual, que consiste no descompasso entre a forma como os alunos estão acostumados aos padrões provenientes da revolução digital e o modelo de ensino tradicional, uma vez que este foi construído sob uma ótica industrial e seriada, opondo-se ao pensamento digital, dinâmico e não-linear (MATTOS, 2017).

O Brasil não é uma exceção a essa realidade. A despeito do vasto acesso à informação adquirido pelos estudantes após a proliferação da Internet e, mais recentemente, dos dispositivos móveis, a taxa de reprovação nas escolas públicas continua praticamente a mesma desde 1997 (INEP, 2016). Mesmo com muitas tentativas de atualizar a sala de aula, há poucas evidências de um significativo impacto no modelo tradicional das escolas, sobretudo as escolas públicas.

Adiciona-se a esse cenário a dificuldade de adaptação do modelo de ensino aos estudantes, que são imersos em um contexto a cada dia mais contrastante com o das escolas. Assim, embora o trabalho prescrito pelas autoridades competentes que elaboram os currículos de ensino nacional seja bem executado, a prática da sala de aula fica a cargo dos professores, que nem sempre conseguem realizar a tradução necessária para os estudantes.

\subsection{Gamificação}

Tendo em vista a problemática exposta, nota-se o surgimento de novas abordagens mais engajadoras ao mindset digital: jogos educativos, simuladores, jogos sérios (serious games) e aprendizagem baseada em jogos digitais. As aplicações destas abordagens podem ser realizadas em cenários de sala de aula, mas também em novos cenários, como corporativo ou até mesmo militar (PRENSKY, 2001).

Outra abordagem que vem transformando o modo tradicional de ensino é o PBL (Problem Based Learning), em tradução livre, aprendizagem baseada em problemas. Segundo Hmelo-silver e Barrows (2006), PBL é um método de aprendizagem ativo baseado no uso de situações-problema estruturadas como estímulo à aprendizagem. Tais situações não possuem necessariamente uma única resposta correta, mas requerem que os educandos considerem as possíveis variáveis que suportem a construção de uma solução. Este tipo de abordagem é frequentemente aplicado em sala de aula para extrair conteúdos teóricos dessas situações problemas.

Entretanto, todas as abordagens listadas possuem característica descendentes, ou seja, se originam a partir de atores com poder centralizado que precisam prever um cenário para depois estruturar o jogo, esperando que aquela aprendizagem específica aconteça. Quando se fala em um método ascendente, no qual primeiramente é analisada a realidade das pessoas envolvidas para se criar um jogo que atenda uma demanda particular, as soluções digitais se tornam caras e de difícil acesso tecnológico. Em contrapartida, as soluções analógicas se tornam pontuais, beirando a superficialidade. 
Desta forma, abre-se espaço para uma abordagem que permite uma análise da motivação atual dos usuários do sistema, de tal forma a criar um processo ascendente que resulta em engajamento, diversão e aprendizagem de maneira acessível e mais significativa: a gamificação.

Gamificação consiste na utilização de elementos e mecânicas de jogos em contextos não lúdicos com o intuito de engajar indivíduos a ação em prol de um objetivo estabelecido (KAPP et al, 2012). Este projeto se utiliza desse conceito como ferramenta que pode diminuir o contraste entre os pensamentos industrial, do ensino tradicional vigente, e digital, tendência presente nas sociedades contemporâneas.

Ao contrário dos outros métodos que empregam jogos em um sistema fechado, a abordagem da gamificação torna possível um delineamento ascendente, partindo do usuário para então se desenvolver no campo do jogo. Para melhor ilustrar esse contraste, foi proposta uma matriz $2 \times 2$ comparativa (Figura 1) entre a função (real ou lúdico) de algumas abordagens de jogos na educação e sua estrutura enquanto sistema (fechado ou aberto).

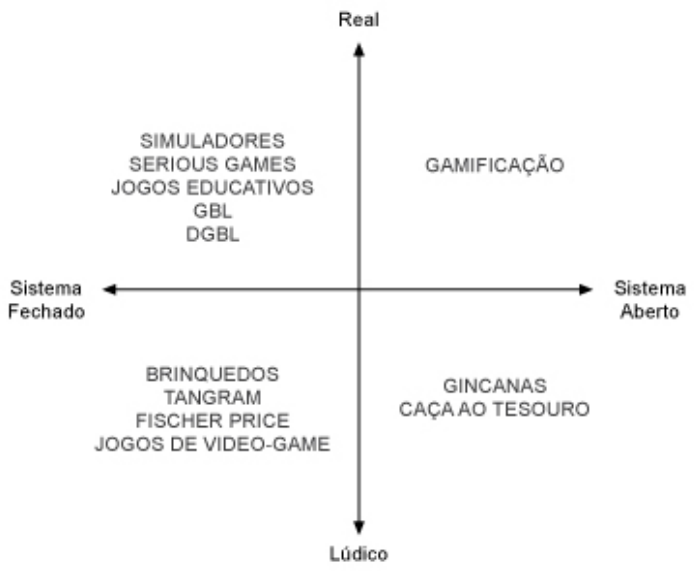

Figura 1: Matriz 2x2 que compara função e estrutura das abordagens interativas.

Nos quadrantes inferiores, as abordagens citadas possuem função lúdica, isto é, com foco no entretenimento do usuário e não a aprendizagem que, quando existente, é consequência da interação. À esquerda encontra-se os sistemas fechados, como brinquedos e jogos de videogame. À direita encontram-se os sistemas abertos como brincadeiras e gincanas. Nos quadrantes superiores, constam as abordagens com função real, isto é, onde o foco principal é a aprendizagem. À esquerda encontra-se

as abordagens de sistema fechado, ou seja, artefatos e jogos. À direita encontra-se a gamificação, que unifica elementos de jogos com contexto não lúdico.

A gamificação é uma abordagem de estrutura aberta e função real e, portanto, é possível torná-la mais aderente ao contexto. Dan Saffer, 2010, afirma que para o design de interação social, qualquer tipo de artefato pode conectar pessoas. O uso da gamificação como instrumento de interação social permite que os designers criem sistemas interativos que facilitem a comunicação entre indivíduos por meio de elementos de jogos.

\section{Método}

A abordagem metodológica baseia-se em dois processos metodológicos: a Análise Ergonômica do Trabalho (AET); e o processo de resolução do problema de design, comumente desenhado por meio do diamante duplo (DESIGN COUNCIL, 2017), que será discutido adiante.

\subsection{A Análise Ergonômica do Trabalho (AET)}

Segundo Abrahão et al (2009), uma ação ergonômica comporta diversas fases, dentre as quais destaca-se para o projeto: análise da demanda, coleta de informações, observações globais e abertas da atividade e elaboração de um pré-diagnóstico.

Durante todo o projeto foram realizadas visitas para observação da atividade de aula na escola, assim como entrevistar os alunos e o professor. Também foi conduzido um grupo focal composto por dois alunos de cada turma (totalizando 8 alunos), pesquisas bibliográficas e reuniões de ideação. $\mathrm{O}$ registro de todas essas informações observadas foi feito em mapas mentais que resultou nos requisitos de prototipação da gamificação.

Apesar de ser inspirado em grande parte na AET, principalmente nas etapas iniciais do processo de aproximação com a escola, conforme as hipóteses surgiam, foram prioritariamente tratadas como descrições de contexto, de tal forma que o processo foi gradualmente perdendo vínculos com as especificidades da AET e ganhando corpo enquanto projeto de design. Dessa maneira, a análise ergonômica serviu como método indutivo dos requisitos que serviram, em seguida, para a proposição da solução do problema de design.

\subsection{Processo de design}


Entende-se que o processo de design possui caráter investigativo e propositivo (SILVA, 2010). Os problemas de natureza complexa frequentemente não apresentam uma única solução estanque e previsível, fazendo-se necessário, portanto, a estruturação do problema para mapear os requisitos que configuram uma solução. Enquanto a análise ergonômica compreende apenas o diagnóstico do contexto, o design permite a ideação de uma solução e a prototipação de um sistema aderente ao contexto (Figura 2).

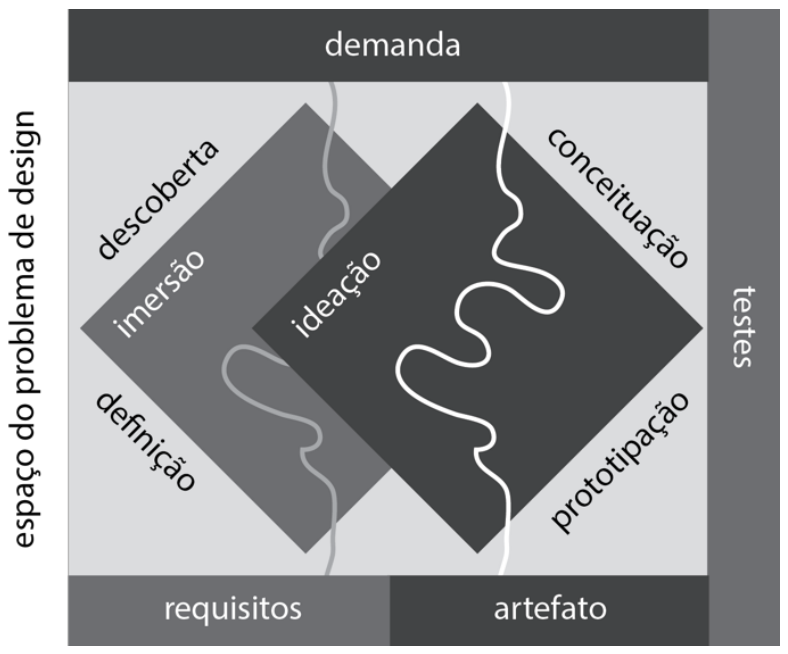

Figura 2: Representação visual dos dois ciclos de ações convergente-divergente do processo de design.

A etapa de estruturação consiste numa imersão dentro do espaço do problema, que resulta na descoberta da demanda, por meio de uma análise divergente, e na definição dos requisitos, obtida pela síntese convergente. Na investigação feita no CED 06 de Ceilândia, esta fase de imersão, foi, justamente, a que incorporou as etapas da AET.

A utilização da AET como estratégia de estruturação do problema de design permitiu um entendimento real do contexto, de caráter imersivo, por meio de entrevistas não-estruturadas abertas, observações globais e observações participativas.

O caráter imersivo presente na etapa de pesquisa visa garantir que o sistema criado convirja para as necessidades reais dos alunos, caracterizando-se como design centrado no usuário (LOWDERMILK, 2013).

\subsection{A análise motivacional}

Desenvolvida após 10 anos de estudos pelo autor e consultor Yu-kai Chou (2015), a Octalysis é uma ferramenta que possibilita uma análise voltada para o usuário de determinado sistema ou serviço.

O autor sintetiza o comportamento decisório humano em oito motivadores universais, e associaos à produtos gamificados, tornando viável a criação planejada de soluções engajadores e divertidas.

Os oito motivadores são (em tradução livre): significado épico e chamado; desenvolvimento e realização; empoderamento da criatividade e feedback; pertencimento e posse; influência relacionamento social; escassez e impaciência; imprevisibilidade e curiosidade; perda e evasão à perda.

Esses motivadores de comportamento são distribuídos numa estrutura octogonal, que se molda conforme a análise é desenvolvida, e busca mostrar ao projetista as lacunas de projeto e o foco para as mecânicas de motivação.

Seu objetivo é viabilizar uma estratégia aderente, e para isso, é necessário conhecer que motivadores são mais relevantes para o usuário. Assim, ela serve como um mapa da relação entre as motivações do usuário e os elementos de jogos mais engajadores para esse público.

Para chegar às informações necessárias para preencher a Octalysis, foi utilizada uma pesquisa estruturada realizada com o grupo focal. A pesquisa contém perguntas para cada motivador, o que permite compreender o peso de cada motivador dentro da realidade dos alunos.

\section{Resultados}

Os resultados foram organizados entre resultados da estruturação do problema de design e resultados de ideação e prototipação da gamificação.

\subsection{Estruturação do problema de design}

O uso das técnicas de pesquisa, como entrevistas, pesquisas dos documentos pedagógicos da escola, observações e análise motivacional a partir do Octalysis, contribuíram para a construção dos requisitos formais da solução.

Durante toda a etapa de pesquisa, os dados coletados foram documentados em mapas mentais, como o que pode ser visto na Figura 3. 


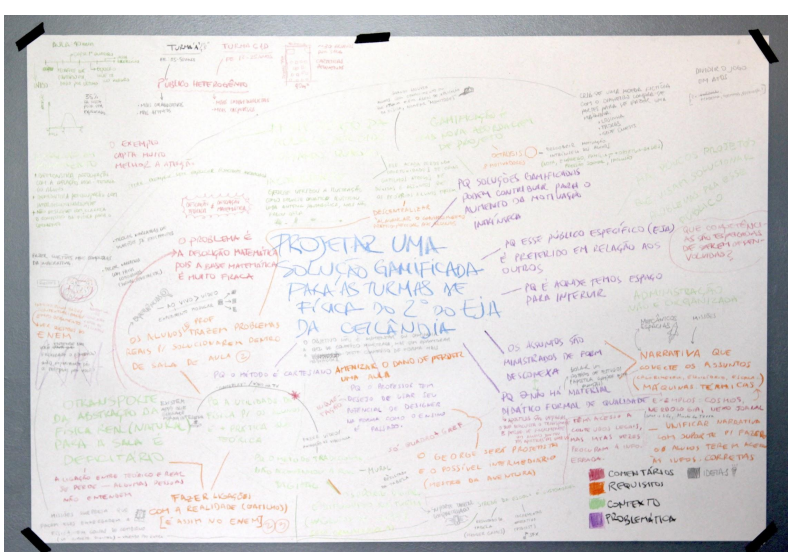

Figura 3: Mapa mental construído durante a etapa de estruturação do problema e levantamento de requisitos.

No centro do mapa localiza-se o objetivo geral do projeto e a partir dele são traçadas as problemáticas observadas. Em seguida, são descritas observações do contexto que justificam tais problemáticas e, por fim, são evidenciados os requisitos de solução.

Com os requisitos devidamente delineados, tornouse possível a geração de alternativas mais palpáveis e adequadas ao contexto. Os requisitos foram organizados em:

- Tornar o conteúdo mais claro por meio de contextualização com a realidade;

- Fazer ligação com a realidade a partir de gatilhos;

- Fazer conexão entre os assuntos por meio de uma narrativa;

- Aproveitar o tempo das aulas e não passar tarefas para serem feitas em casa, garantindo que as dúvidas sejam sanadas;

- Utilizar mídias digitais de forma acessível;

- Alavancar o conhecimento prático pessoal dos alunos;

- Alunos e professor podem trazer problemas reais para solucionarem em sala de aula;

- Passar sensação de controle sobre as atividades e conteúdos aprendidos por meio de feedbacks instantâneos;

- Tornar a solução engajadora para todas as turmas e sua diversidade de alunos;
- Garantir o uso de mecânicas de jogos que estejam dentro do âmbito dos motivadores: Aversão à Perda, Significado Épico e Realização, identificados como centrais no grupo focal;

- Repensar a utilização do material didático, criando um roteiro de estudos com conteúdos autorais do professor, para que um dia substituam as apostilas.

\subsection{Fase de Ideação}

O processo de ideação foi construído paulatinamente ao longo do projeto e pode-se entender que houve três ciclos de iteração: uma geração livre e exploratória, sem muita preocupação em adequação ao contexto, uma segunda iteração contextual, mais aderente após os primeiros resultados das pesquisas e por fim uma última iteração co-criativa, dividida em vários encontros que contaram com participação ativa do professor da disciplina.

Para cada requisito levantado na pesquisa de estruturação foi designado um ou mais atributos capazes de contemplá-la, como pode ser observado no quadro 1 .

\begin{tabular}{|c|c|}
\hline Requisitos & Atributos \\
\hline $\begin{array}{l}\text { Clareza: (1) Tornar o } \\
\text { conteúdo mais claro por meio } \\
\text { de contextualização com a } \\
\text { realidade; (2) Fazer ligação } \\
\text { com a realidade a partir de } \\
\text { gatilhos; (3) Fazer conexão } \\
\text { entre os assuntos por meio } \\
\text { de uma narrativa; }\end{array}$ & $\begin{array}{l}\text { (1) Usar abordagem inspirada } \\
\text { em Problem Based Learning } \\
\text { (PBL); (2) Usar exemplos } \\
\text { reais e cotidianos na } \\
\text { construção de exercícios de } \\
\text { fixação; (3) Dividir os } \\
\text { assuntos em ciclos de } \\
\text { conhecimento } \\
\text { hierarquizados, de tal forma } \\
\text { que comece pelo mais } \\
\text { complexo e aplicável } \\
\text { (Máquinas Térmicas, no caso } \\
\text { a Geladeira), e o professor } \\
\text { possa puxar os conteúdos } \\
\text { teóricos a partir disso (a } \\
\text { exemplo, Transformação } \\
\text { Isobárica); }\end{array}$ \\
\hline $\begin{array}{l}\text { Aproveitar o tempo das aulas } \\
\text { e não passar tarefas para } \\
\text { serem feitas em casa, } \\
\text { garantindo que as dúvidas } \\
\text { sejam sanadas; }\end{array}$ & $\begin{array}{l}\text { Propor uma nova estrutura de } \\
\text { aula, aproveitando melhor os } \\
40 \text { minutos de aula, de uma } \\
\text { maneira que conecte os } \\
\text { assuntos de todas as aulas à } \\
\text { narrativa de Máquinas } \\
\text { Térmicas: } 1^{\circ} \text { ) Recapitulação; } \\
\left.2^{\circ} \text { ) Situação Problema; } 3^{\circ}\right) \\
\text { Explicação e Resolução do } \\
\text { Exercício; } 4^{\circ} \text { ) Check out; }\end{array}$ \\
\hline
\end{tabular}




\begin{tabular}{|c|c|}
\hline $\begin{array}{l}\text { Utilizar mídias digitais de } \\
\text { forma acessível a todos; }\end{array}$ & $\begin{array}{l}\text { Criar grupos de whatsapp } \\
\text { para cada turma onde os } \\
\text { exercícios possam ser } \\
\text { passados para ganhar tempo } \\
\text { de aula. Dividir a sala em } \\
\text { grupos de, no mínimo, } 4 \\
\text { (quatro) alunos, de tal forma } \\
\text { que, pelo menos } 1 \text { (um) aluno } \\
\text { tenha celular; }\end{array}$ \\
\hline $\begin{array}{l}\text { Descentralização: (1) } \\
\text { Alavancar o conhecimento } \\
\text { prático pessoal dos alunos; } \\
\text { (2) Alunos e professor podem } \\
\text { trazer problemas reais para } \\
\text { solucionarem dentro de sala } \\
\text { de aula; }\end{array}$ & $\begin{array}{l}\text { (1) Criar um momento para } \\
\text { que os alunos discutam entre } \\
\text { si e possam ensinar os } \\
\text { conteúdos com suas } \\
\text { palavras; (2) Abordagem } \\
\text { inspirada em PBL; }\end{array}$ \\
\hline $\begin{array}{l}\text { Passar sensação de controle } \\
\text { sobre as atividades e } \\
\text { conteúdos aprendidos } \\
\text { através de feedbacks } \\
\text { instantâneos; }\end{array}$ & $\begin{array}{l}\text { Implementar o uso de uma } \\
\text { cartilha de vistos, onde os } \\
\text { alunos podem completar o } \\
\text { desenho da Geladeira, } \\
\text { através de adesivos } \\
\text { colecionáveis, conforme } \\
\text { aprendam sobre cada } \\
\text { componente dela, } \\
\text { demonstrando o avanço feito } \\
\text { a cada aula; }\end{array}$ \\
\hline $\begin{array}{l}\text { Tornar a solução engajadora } \\
\text { para todas as turmas e sua } \\
\text { diversidade de alunos; }\end{array}$ & $\begin{array}{l}\text { Utilizar as características de } \\
\text { Dynamic Difficulty Adjustment } \\
\text { (DDA) em avaliações no } \\
\text { estilo de prova; }\end{array}$ \\
\hline $\begin{array}{l}\text { Garantir o uso de mecânicas } \\
\text { de jogos que estejam dentro } \\
\text { do âmbito dos motivadores } \\
\text { positivos para reduzir o } \\
\text { motivador de Aversão à } \\
\text { Perda: (1) Significado Épico, } \\
\text { (2) Realização e (3) } \\
\text { Empoderamento da } \\
\text { Criatividade; }\end{array}$ & $\begin{array}{l}\text { Usar mecânica Narrativa (1), } \\
\text { Barra de Progresso (2), } \\
\text { Troféus (2), Desbloqueio de } \\
\text { Marco (3), Feedback } \\
\text { Instantâneo (3), entre outras, } \\
\text { de outros motivadores, como, } \\
\text { Missões em Grupo, Efeito } \\
\text { Oráculo e Conjuntos } \\
\text { Colecionáveis; }\end{array}$ \\
\hline $\begin{array}{l}\text { Repensar a utilização do } \\
\text { material didático, criar um } \\
\text { roteiro de estudos com } \\
\text { conteúdos autorais do } \\
\text { professor, para que um dia } \\
\text { substituam as apostilas; }\end{array}$ & $\begin{array}{l}\text { Fazer um blog exclusivo para } \\
\text { a matéria de acesso fácil e } \\
\text { gestão, e permita divisão dos } \\
\text { assuntos, aceite vídeos, } \\
\text { permita downloads e seja } \\
\text { amigável para o professor e } \\
\text { para os alunos. }\end{array}$ \\
\hline
\end{tabular}

Quadro 1: Requisitos e atributos relacionados na fase de ideação do projeto.

Pode-se constatar que a solução aconteceu em três campos: estrutural, analógico e digital. Por se tratar de um sistema complexo que leva em conta as variáveis da aprendizagem dos alunos do CED 6, a gamificação inverteu a lógica pedagógica, manifestou-se em artefatos analógicos e incluiu recursos digitais na aprendizagem de física.

\section{Solução no campo estrutural}

A primeira grande mudança no método de aprendizagem foi a criação de uma narrativa sobre a geladeira. Um dos principais requisitos era o de alavancar o conhecimento prático pessoal dos alunos, fugindo da abstração dos números para criar gatilhos de conhecimentos fáceis de serem lembrados.

Para fazê-lo foi proposta a inversão dos conteúdos didáticos, que antes começavam com os conceitos mais abstratos e básicos, para chegarem na complexidade das máquinas térmicas somente no final do período letivo. Portanto, criou-se a narrativa sobre o funcionamento da geladeira, que é um eletrodoméstico conhecido, para que a partir dele os alunos possam estudar os seus componentes que se desdobram em conteúdos mais teóricos e abstratos, como pode ser visto na Figura 4.

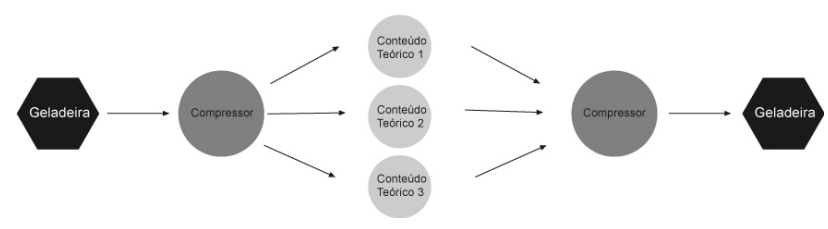

Figura 4: Ciclo de aprendizagem a partir da máquina térmica (geladeira) seguindo para componente (compressor) divergindo para conceitos teóricos.

Partindo da abordagem educacional baseada em problemas (PBL), o fluxo de funcionamento em sala de aula também foi invertido. Nos períodos em que antes havia um longo momento de cópia no quadro, seguido de explicação expositiva e, por fim, execução de exercícios, foram sugeridos um momento de (1) recapitulação do conteúdo visto nas aulas anteriores, para que em seguida fosse passada uma (2) situação problema, que os alunos devem tentar responder evocando a bagagem de conteúdos que possuem, para então, pararem para um momento de (3) explicação do professor.

Entende-se que, desta forma, o professor passa a ser um facilitador do conhecimento, não mais um centralizador. Por fim, é realizado um (4) check out que é o momento em que os alunos recebem o feedback de seu progresso na aprendizagem da geladeira (Figura 5).

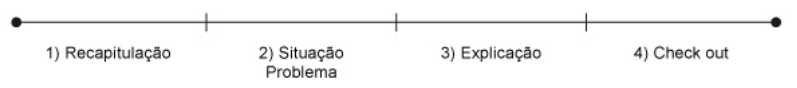

Figura 5: Fluxo de organização das aulas.

É importante ressaltar que na etapa de situação problema, o professor teve a liberdade de explorar 


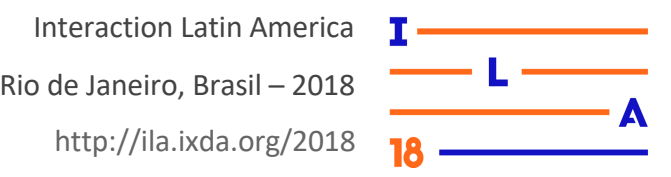

três tipos de circunstância: experimentos em salade-aula, no qual o professor pode evidenciar uma aplicação real da física no dia-a-dia; cartas de exercícios, designadas a conter a situação problema; e cartões de webquest designados à avaliação para conclusão do conteúdo teórico contido no componente da geladeira em questão. As cartas de exercícios e os cartões de webquest são descritos mais à frente.

\section{Solução no campo analógico}

Para fins de tangibilidade entre a narrativa e os processos de sala de aula como, por exemplo, explicação, exercícios e avaliação de notas, foram criados artefatos impressos em que os alunos poderiam interagir.

O primeiro artefato foi um banner de direcionamento do conteúdo, no qual os alunos podem ver a anatomia da geladeira, bem como, quais conteúdos teóricos estão associados em cada componente (Figura 6).

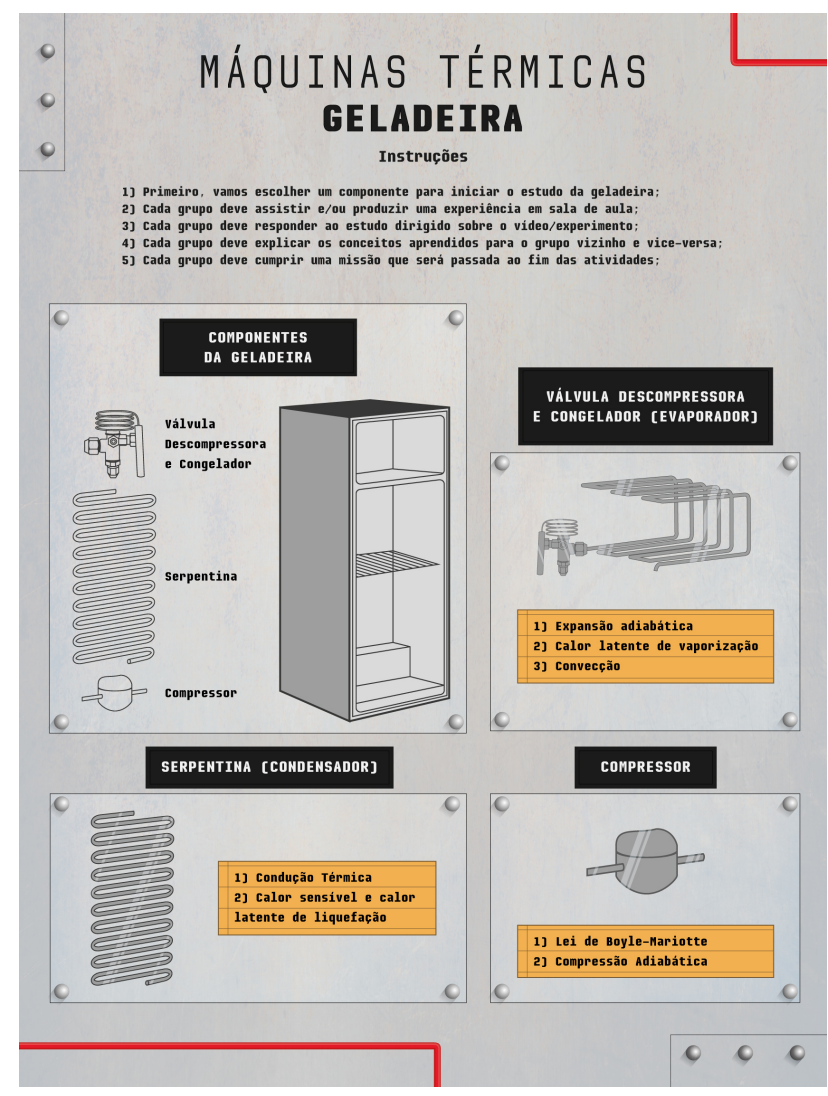

Figura 6: Banner de direcionamento do conteúdo baseado na anatomia da geladeira.

O banner consiste na porta de entrada para a gamificação. Portanto, para o melhor entendimento e leitura, foram concebidas ilustrações da geladeira e seus componentes, seguindo a identidade visual proposta para o projeto. Ele possui 60 centímetros de largura e 80 centímetros de altura, podendo ser impresso em papel ou vinil. O banner comporta, também, instruções de como se traduzirá o ciclo de aprendizagem a partir da narrativa dentro do processo de sala de aula.

Para acompanhamento e controle de qual componente está sendo estudado naquele momento, foi criada uma cartilha de adesivos com a mesma anatomia da geladeira. Dessa forma, os alunos recebiam recompensas (os adesivos) ao completarem o ciclo referente àquele componente específico.

Essa cartilha, juntamente com os adesivos, estruturam a mecânica de conjuntos colecionáveis e são uma forma de reduzir o motivador de aversão à perda, dando ao aluno a sensação de controle sobre sua própria trajetória. $\mathrm{O}$ artefato pode ser visto na Figura 7.

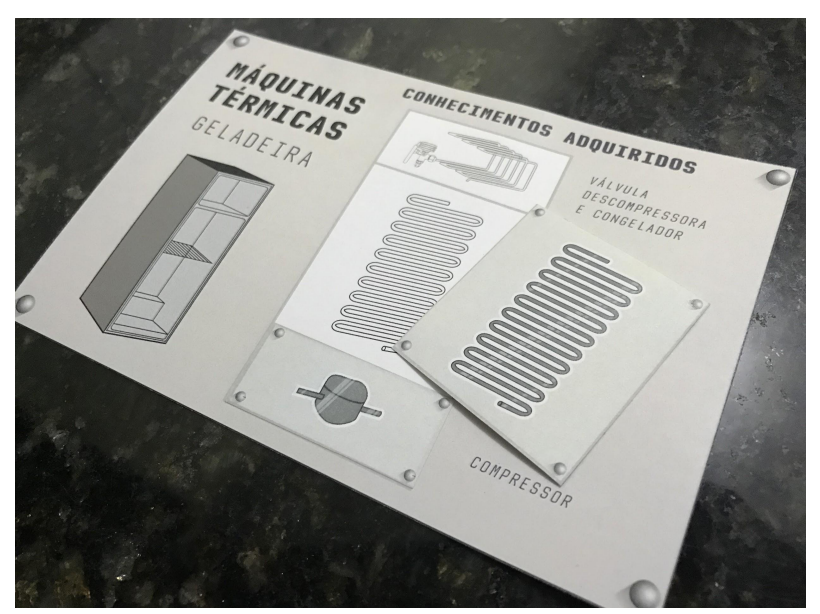

Figura 7: Cartilha de adesivos.

\section{Solução no campo digital}

O uso do campo digital na solução surgiu para preencher as lacunas entre a educação em sala de aula e a velocidade do pensamento digital dos alunos. A solução se deu em dois ambientes virtuais: um blog criado para o projeto e em grupos de WhatsApp.

O blog foi criado usando a ferramenta Wix. A escolha de uso da ferramenta ocorreu porque foi considerada de fácil atualização, o que facilita a alimentação de conteúdos por parte do professor. Além disso, a centralização do conhecimento e dos 


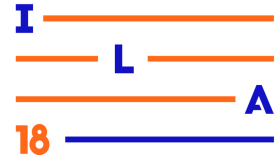

exercícios em um blog deve facilita o acesso dos alunos aos conteúdos.

O blog foi dividido por turmas, sendo que cada sessão contém uma barra de progresso da turma. A barra, nomeada como "painel da evolução", contém o componente estudado durante aquele período e se os grupos de alunos haviam completado as atividades referentes àquele conhecimento. $\mathrm{O}$ feedback para controle dos usuários é determinado por uma luz que acende quando as aulas daquele conhecimento são realizadas (Figura 8).

a)

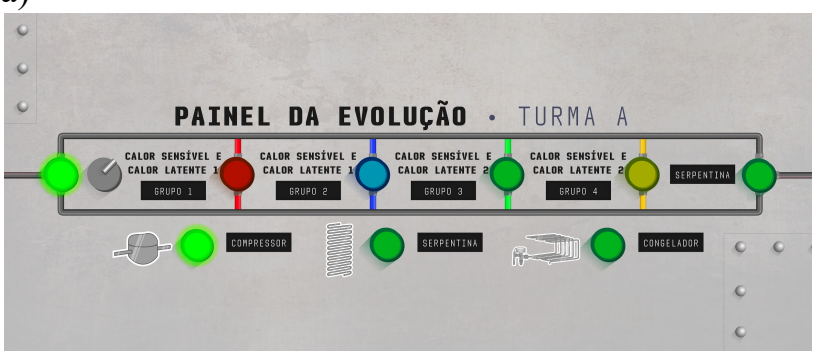

b)

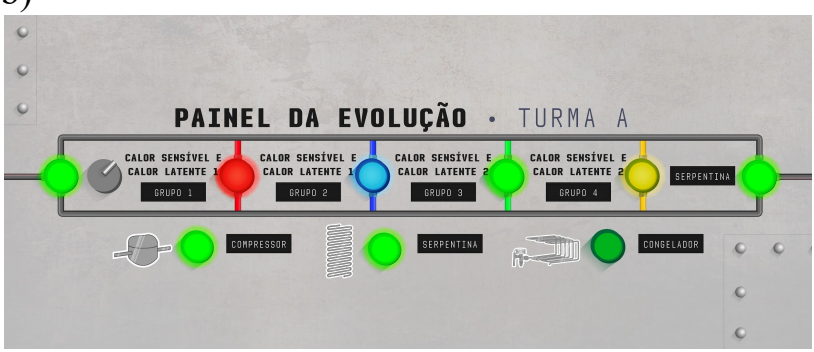

Figura 8: Barra de progresso das turmas indicando os conteúdos do compressor. Em "a" o painel indica que a turma A não completou as atividades. Em "b" o painel indica que a turma completou as atividades e que o próximo componente é a serpentina.

O segundo ambiente utilizado foi o aplicativo WhatsApp. Os grupos se tornaram um importante canal de comunicação entre o professor e a turma, pois as cartas de exercícios e os cartões de webquests eram passados por esse meio (Figuras $9 \mathrm{e}$ $10)$.

Ambos os cartões são produzidos por meio de imagens no formato .jpeg enviadas dentro dos grupos de WhatsApp. Ambas contribuem para o avanço na barra de progresso da turma para que, desta forma, tanto o professor quanto os alunos saibam qual conhecimento está sendo aprendido, o que mitiga ainda mais a aversão à perda constatada na etapa de pesquisa.

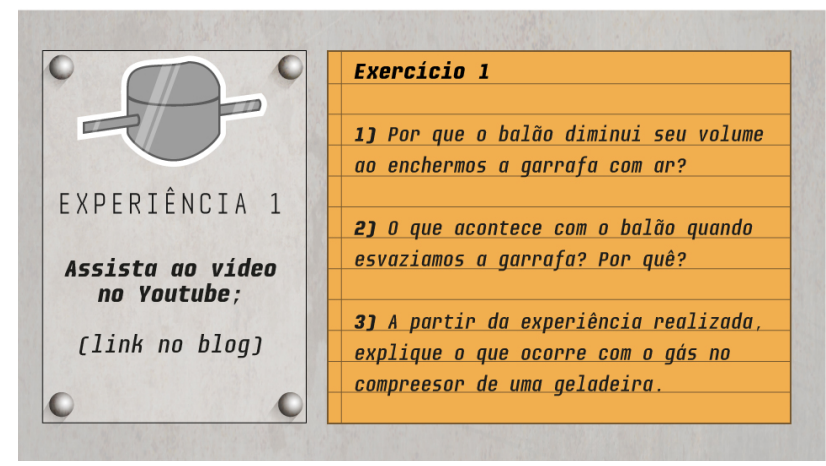

Figura 9: Carta de Exercícios com instruções de como proceder com a atividade.

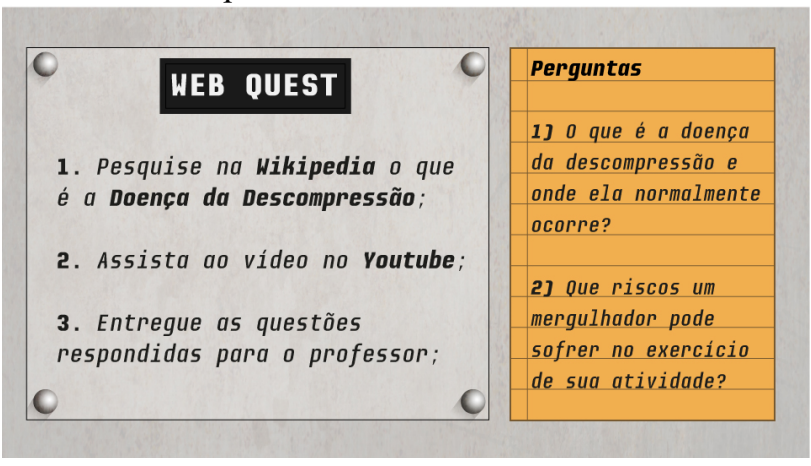

Figura 10: Cartão de webquest com instruções de como proceder à avaliação.

Os exercícios que são aplicados por meio dos cartões de exercício e de webquest, também foram todos disponibilizados no blog por meio de postagens. A plataforma permite a visualização de vídeos do Youtube direto no $b l o g$, o que facilita o uso e a sua adoção em sala de aula.

Outras funcionalidades interessantes foram propositalmente deixadas de lado para a fase de testes, como, login, comentários e downloads.

\section{Discussão}

O desenvolvimento desse trabalho aponta para uma percepção considerada atual do processo de design, em que o objeto de estudo não é necessariamente tangível, embora possa abarcá-lo, mas sobretudo a articulação das interações dentro de um sistema.

Problemas reais inseridos em contextos complexos convidam designers a abandonarem suas zonas de conforto e buscarem a compreensão do funcionamento do sistema. Embora esse seja um convite desafiador, a experiência dos autores obtida com esse projeto reforça a validade de aceitá-lo, como reforça Cardoso (2016). 
A perspectiva adotada no desenvolvimento desse projeto é consoante com as afirmações do autor: o projeto desenvolvido em campo, com aprofundamento em contexto torna toda a solução mais aderente.

Durante o desenvolvimento do projeto, as etapas iniciais de imersões foram mais longas e detalhadas, demonstrando a importância dedicada à compreensão profunda do contexto do projeto. Uma situação interessante que exemplifica essa realidade é percebida na fase de geração livre de alternativas em que, para fins de criatividade, o contexto não foi levado em conta por alguns instantes e várias possíveis soluções foram propostas.

Uma delas envolvia a criação de uma narrativa espacial, com muitas possibilidades de gamificação em vários elementos: a atribuição de papéis específicos a cada indivíduo segundo suas aptidões profissionais, mecânicas de bens virtuais, entre outros. Sob muitas óticas, a ideia tinha sim potencial, mas bastou confrontá-la com a realidade para perceber que não haveria aderência ao contexto: mais da metade do público-alvo é adulto, com pouca aceitação de contexto lúdicos; a mecânica de bens virtuais não é a mais importante para eles, uma vez que visa o estímulo de pertencimento e posse, que não é o principal motivador detectado. Percebe-se, portanto, o quanto projeto teria se empobrecido caso não houvesse a centralidade no usuário e a compreensão do contexto.

A centralidade do projeto no usuário é de suma importância, sobretudo em contextos complexos. O motivo pelo qual esse projeto justifica-se enquanto um projeto de design é exatamente esse, pois designers estão (ou deveriam estar) habituados a lidar com projetos desenvolvidos em torno do usuário.

No início da década de 70, quando Victor Papanek publicou seu livro Design for the real world (Design para o mundo real), o autor incomodou a comunidade ao expor essa ideia da inobservância da realidade, o que até hoje incomoda a muitos projetistas.

A transformação da realidade, especialmente uma realidade complexa como é a que se encontram as sociedades atuais, exige a interação de vários agentes. Por esse motivo é importante que o design seja de interação com as diversas partes de um sistema, aliando, confrontando e acomodando

variados pontos de vista de modo obter uma construção aderente ao contexto.

É pouco provável que a solução proposta nesse projeto represente um avanço na Educação de Jovens e Adultos do Distrito Federal isoladamente. Embora o resultado atingido tenha envolvido o melhor esforço dos designers responsáveis, deve-se reconhecer que ainda há inúmeros desafios que extrapolam os limites da sala de aula, e isso não deve ser motivo de frustração. Por essa razão é importante que os objetivos de cada projeto sejam realistas e objetivos. No caso do presente projeto, o escopo é bem delimitado: impactou um universo de apenas sessenta alunos de uma disciplina, todos da modalidade de Ensino de Jovens e Adultos, dentro de apenas uma escola, dentro de uma cidade, dentro de somente um dos vinte e sete estados brasileiros.

Dentro do contexto nacional, esse impacto pode ser considerado muito pequeno. Contudo, é questionável a viabilidade de qualquer projeto que prometa transformar uma realidade complexa como essa em um prazo curto como esse com um alto impacto.

É ainda muito cedo para saber o quão eficaz foi o projeto realizado, trabalho ainda em andamento pela pesquisa a qual o presente projeto está vinculado. É importante, contudo, ressaltar que o público-alvo delimitado nesse projeto carece de um projeto de educação focado nas suas necessidades.

O que se percebe ao observar a realidade de EJA é que se trata de uma replicação do formato de ensino tradicional que não leva em conta o contexto. Sendo ainda mais realista, o próprio modelo tradicional já vem, há anos, sofrendo muitas críticas e sendo considerado inadequado.

Assim, se faz relevante também, o papel do professor. O presente projeto é fruto de uma inquietação do professor da escola investigada, sem o qual esse projeto certamente não teria tocado a dimensão da realidade. Ainda, é necessário ressaltar a importância dos cursos de formação específicos para a modalidade de EJA.

\section{Considerações}

O projeto aqui apresentado conclui-se com uma análise qualitativa acerca da proposta de intervenção que puderam ser percebidos em uma aplicação inicial. No início do mês de novembro de 2017 
testou-se a proposta em sala de aula a fim de verificar a aceitação pelo público-alvo. A impressão inicial registrada pelo professor é positiva: alunos que não costumavam participar tanto da aula passaram a se interessar mais, e o uso de experimentos despertou a curiosidade de muitos. É importante mencionar uma observação do professor a respeito do desafio dessa abordagem quanto a sua vulnerabilidade à interrupções, pois o uso da narrativa da geladeira necessita de continuidade até que termine, de tal forma que intervalos no ciclo de aprendizagem são prejudiciais. Por se passar em uma instituição de ensino pública, interrupções como greves de servidores em diversos campos atrapalharam a apreensão da narrativa e, por consequência, do conhecimento gerado a partir dela.

Conclui-se que a gamificação tem o potencial eminente de ser usado como ferramenta de interação social capaz de conectar indivíduos. A escolha por uma gamificação, de natureza aberta e real, adiciona ao projeto a qualidade de poder ser aderente ao contexto de trabalho, diferente de uma solução mais rígida e pouco adaptável; outra consequência direta dessa característica é a facilidade para se atualizar o projeto, uma vez que ele não é exclusivamente digital. Finalmente, o engajamento do público é também uma qualidade esperada dessa abordagem na medida em que torna a tarefa do usuário mais clara, prazerosa e motivadora.

\section{Referências Bibliográficas}

ABRAHAO, Julia et al. Introdução a ergonomia: da prática a teoria. Brasil: Edgard Blucher, 2009. $240 \mathrm{p}$.

BRASIL. Instituto Nacional de Estudos e Pesquisas Educacionais Anísio Teixeira. Inep divulga dados inéditos sobre fluxo escolar na educação básica. 2017. Disponível em:

$<$ http://portal.inep.gov.br/artigo//asset_publisher/B4AQV9zFY7Bv/content/inepdivulga-dados-ineditos-sobre-fluxo-escolar-naeducacao-basica/21206>. Acesso em: 9 ago. 2017.

\section{CHOU, Yu-kai. Gamification \& behavioral}

design. 2015. Disponível em:

$<\mathrm{http}$ ://yukaichou.com/gamification-

examples/octalysis-complete-gamification-

framework/>. Acesso em: 23 out. 2017.
DESIGN COUNCIL (United Kingdom). Designers across disciplines share strikingly similar approaches to the creative process, which we've mapped out as 'the Double Diamond'. c2017.

Disponível em:

$<$ http://www.designcouncil.org.uk/newsopinion/design-process-what-double-diamond $>$. Acesso em: 15 set. 2017.

HMELO-SILVER, Cindy E.; BARROWS, Howard S. Goals and Strategies of a Problem-based Learning Facilitator. Interdisciplinary Journal of Problem-based Learning, [s.1.], v. 1, n. 1, p.1-39, 22 maio 2006. Purdue University (bepress). http://dx.doi.org/10.7771/1541-5015.1004. Disponível em:

$<$ http://docs.lib.purdue.edu/ijpbl/vol1/iss1/4/>. Acesso em: 16 set. 2017.

KAPP, Karl M.; BLAIR, Lucas; MESCH, Rich. The gamification of learning and instruction fieldbook: ideas into practice. United States: Pfeiffer, 2013. 480 p.

LOWDERMILK, Travis. User-Centered Design: A developer's guide to building user-friendly applications. 2013. $184 \mathrm{p}$

MATTOS, Tiago. Vai lá e faz: como empreender na era digital e tirar ideias do papel. 2017. Disponível em:

$<\mathrm{http}$ //assets.perestroika.com.br.s3.amazonaws.com /vlef/vlef.pdf $>$. Acesso em: 18 julho 2017.

PRENSKY, Marc. Digital game-based learning. United States: Paragon House, 2001. 464 p.

SAFFER, Dan. Designing Gestural Interfaces. 2010. $270 \mathrm{p}$.

SILVA, Tiago Barros Pontes e. Um campo epistemológico para o Design. 2015. Disponível em: <http://periodicos.unb.br/index.php/designtecnologia-sociedade/article/view/19968/14157>. Acesso em: 16 set. 2017.

\section{Agradecimentos}

Agradecemos pela oportunidade de ter acesso à educação pública e gratuita de qualidade, com a qual esperamos contribuir com a presente pesquisa. Por mais investimentos em educação no Brasil. 